\title{
ANALISIS KINERJA BADAN PENANAMAN MODAL DAN PELAYANAN PERIZINAN KABUPATEN BANYUMAS DALAM PELAYANAN IZIN MENDIRIKAN BANGUNAN
}

\author{
Bahrudin, Ali Rokhman, Sukarso ${ }^{1}$
}

\begin{abstract}
ABSTRAK
Jenis penelitian yang digunakan dalam penelitian ini adalah mix method dengan strategi metode campuran konkruen/ sewaktu-waktu (concruent mixed methods) terutama strategi embedded konkruen. Populasi dalam penelitian ini adalah seluruh masyarakat yang pernah mengurus IMB di BPMPP Kabupaten Banyumas pada tahun 2015. Permohonan Pelayanan IMB pada BPMPP Kabupaten Banyumas Tahun 2015 adalah sejumlah 256 permohonan. Sampel yang diambil sebanyak $40 \%$ dari jumlah populasi, dengan perhitungan $40 \%$ x 256 $=102$ sampel. Penelitian ini menilai kinerja organisasi BPMPP Kabupaten Banyumas dengan mengacu pada lima dimensi kinerja yang meliputi produktivitas, kualitas layanan, responsivitas, responsibilitas dan akuntabilitas. Analisis data menggunakan analisis distribusi frekfuensi dalam bentuk nilai ratarata dan dalam bentuk kategori rendah, sedang atau tinggi.

Hasil penelitian menunjukkan bahwa 1) Produktivitas layanan IMB di BPMPP Kabupaten Banyumas masih rendah, hal ini dapat dilihat dari persebaran jawaban responden terhadap dimensi produktivitas layanan IMB yang masuk kategori rendah; 2) Kualitas layanan IMB di BPMPP Kabupaten Banyumas masih rendah, hal ini dapat dilihat dari persebaran jawaban responden terhadap dimensi kualitas layanan IMB yang masuk kategori rendah; 3) Responsivitas layanan IMB di BPMPP Kabupaten Banyumas masih rendah, hal ini dapat dilihat dari persebaran jawaban responden terhadap dimensi responsivitas layanan IMB yang masuk kategori rendah; 4) Responsibilitas layanan IMB di BPMPP Kabupaten Banyumas masih rendah, hal ini dapat dilihat dari persebaran jawaban responden terhadap dimensi responsibilitas layanan IMB yang masuk kategori rendah; 5) Akuntabilitas Layanan IMB di BPMPP Kabupaten Banyumas masih rendah, hal ini dapat dilihat dari persebaran jawaban responden terhadap dimensi akuntabilitas layanan IMB yang masuk kategori rendah
\end{abstract}

Kata Kunci: Akuntabilitas, Kinerja, Kualitas Layanan, Produktivitas, Responsibilitas, Responsivitas

\footnotetext{
${ }^{1}$ Program Magister Ilmu Administrasi Publik, Universitas Jenderal Soedirman
} 


\begin{abstract}
This research uses mixed method research strategy mixed methods konkruen / anytime (concruent mixed methods) mainly embedded konkruen strategy. The study population was the whole community submitting BPMPP IMB in Banyumas in 2015. Type Services IMB on BPMPP Banyumas in 2015 amounted to 256 petition. Samples taken as many as $40 \%$ of the total population, with the calculation of $40 \% \times 256=102$ samples. This study aims to assess the organization's performance BPMPP Banyumas with reference to the five dimensions of performance that include productivity, quality of service, responsiveness, responsibility and accountability. Data analysis using frequency distribution analysis in the form of average values and into categories of low, medium or high.

The results showed that 1) Productivity IMB services in BPMPP Banyumas is still low, as indicated by the spread of the respondent's answer to the dimensions of productivity IMB services are categorized as low; 2) Quality of service IMB in BPMPP Banyumas is still low, which looks at the distribution of respondents' answers to the dimensions of service quality in the category of low BMI; 3) Responsiveness IMB services in BPMPP Banyumas is still low, which looks at the distribution of respondents' answers to the dimensions of the responsiveness of $I M B$ services are categorized as low; 4) Responsibility IMB services in BPMPP Banyumas is still low, as demonstrated by the distribution of respondents to the dimensions of responsibility IMB services are categorized as low; 5) Accountability IMB Service in BPMPP Banyumas is still low, which looks at the distribution of respondents' answers to the dimensions of accountability IMB services are categorized as low.
\end{abstract}

Keyword : Accountability, Performance, Quality of service, Productivity, Responsibility, Responsiveness

\title{
A. PENDAhuluan
}

Badan Penanaman Modal dan Pelayanan Perizinan (BPMPP) Kabupaten Banyumas adalah garda terdepan dalam pelayanan perizinan di wilayah Kabupaten Banyumas selalu berupaya untuk memberikan pelayanan terbaik kepada masyarakat pengguna layanan, dengan mengacu pada Peraturan Daerah Kabupaten Banyumas Nomor 17 tahun 2011 tentang Perubahan Kedua atas Peraturan Daerah Kabupaten Banyumas Nomor 27 tahun 2009 tentang Organisasi dan Tata Kerja Lembaga Teknis Daerah Kabupaten Banyumas dan Peraturan Bupati Banyumas Nomor 50 Tahun 2014 tentang Pendelegasian Wewenangan Perizinan kepada Kepala Badan Penanaman Modal dan Pelayanan Perizinan, Pemerintah Kabupaten Banyumas. Dalam ketentuan ini secara tegas diatur tentang jenis layanan, 
persyaratan layanan, jangka waktu layanan serta besarnya biaya layanan. Menurut ketentuan Peraturan daerah ini ada 58 jenis layanan perizinan yang dilakukan oleh BPMPP Kabupaten Banyumas.

Izin mendirikan bangunan sebagai salah satu bagian dari perizinan yang ada di BPMPP Kabupaten Banyumas juga tak luput dari adanya kekurangan dan kendala dalam pelayanannya, walupun telah memiliki Standar Operasional Prosedur yang jelas. Berikut ini data mengenai pelayanan perizinan Izin Mendirikan Bangunan di Kabupaten Banyumas

Tabel. Data Rekapitulasi Pelayanan IMB Januari-Juni 2015

\begin{tabular}{|l|l|l|l|l|l|}
\hline \multirow{2}{*}{ No } & Jenis Layanan & \multicolumn{2}{|c|}{ Jangka Waktu layanan } & \multicolumn{2}{c|}{ Persentase } \\
\cline { 3 - 6 } & $\begin{array}{l}\text { Sesuai SOP } \\
(14 \text { hari })\end{array}$ & $\begin{array}{l}\text { Belum Sesuai SOP } \\
\text { (lebih dari 14 hari) }\end{array}$ & & \\
\hline 1 & $\begin{array}{l}\text { Izin Mendirikan } \\
\text { Bangunan }\end{array}$ & 20 & 236 & $7,8 \%$ & $92,2 \%$ \\
\hline
\end{tabular}

Sumber: Data BPMPP, 2015

Tabel di atas menunjukkan bahwa pelayanan izin mendirikan bangunan masih belum sesuai dengan SOP yakni 14 hari pelayanan sebesar $92,2 \%$, sedangkan pelayanan perizinan yang telah memenuhi SOP yakni 14 hari pelayanan baru sebesar 7.8\%. Hal ini menujukkan bahwa kinerja pelayanan perizinan utamanya pelayanan perizinan IMB di Kabupaten Banyumas yang dalam hal ini dilakukan oleh BPMPP masih belum sesuai dengan harapan masyarakat. Lambatnya pelayanan perizinan ini ditengarai karena perilaku birokrat yang mempersulit proses perizinan, hal ini sesuai dengan apa yang disampaikan oleh Menko Maritim Rizal Ramli yang menyatakan bahwa:

"Kalau enggak dipotong jadi makin ribet, makin jadi sumber pendapatan. Dulu dikalangan birokrat ada pepatah, kalau bisa dibikin sulit, kenapa dibikin mudah”.(Detikcom, 31 Agustus 2015)

Mendasarkan pada penjelasan di atas, peneliti tertarik untuk meneliti dengan meminta pendapat masyarakat terkait kinerja layanan perizinan Izin Mendirikan Bangunan (IMB), sebab berdasarkan penjelasan sebelumnya terlihat bahwa masyarakat secara umum cenderung memandang kinerja 
layanan bidang perizinan IMB yang dilakukan oleh BPMPP Kabupaten Banyumas masih buruk

\section{Penelitian Terdahulu}

Yonanda (2015) dalam penelitiannya menyebutkan bahwa Kantor Pelayanan Perizinan Terpadu (KPPT) dinilai kurang mandiri dalam memberikan pertimbangan dan keputusan. Ditambah faktor standar minimal yang ditetapkan dalam pelayanan Izin Mendirikan Bangunan (IMB) masih kurang jelas.

Hasil penelitian Pane (2012) menunjukan bahwa faktor yang berpengaruh dalam kualitas pelayanan adalah kondisi sarana dan parasarana yang tidak memadai, kekurangan jumlah pegawai, kemampuan pegawai yang belum menciptakan pelayanan yang baik, cepat, dan memuaskan. Hal tersebut dikarenakan belum adanya SOP yang mengatur atau belum masuk dalam standar pelayanan prima.

Hasil penelitian Use the "Insert Citation" button to add citations to this document.

Ritz (2009) menunjukan bahwa faktor dalam meningkatkan kinerja organisasi adalah kepuasan kerja karyawan, komitmen organisasi, dan motivasi pelayanan publik. Selanjutnya Rahmawati (2012) dalam penelitiannya menyebutkan bahwa faktor yang paling besar pengaruhnya terhadap kinerja pegawai adalah pendidikan terakhir. Demikian pula Saniadi (2008) dalam hasil penelitiannya menyebutkan bahwa kinerja Kantor Pelayanan Terpadu dan Perijinan Kabupaten Grobogan masih tergolong rendah, sehingga masih perlu ditingkatkan lagi.

Perbedaan penelitian ini dengan penelitian sebelumnya adalah pada model yang dipergunakan dalam meneliti kinerja layanan. Beberapa penelitian terdahulu mempergunakan model kepuasan terhadap layanan publik, mereka lebih menitikberatkan perhatian pada penilaian dari sisi internal pegawai seberapa puas pengguna layanan terhadap layanan publik, sementara penelitian ini menitikberatkan penilaian kinerja layanan yang lebih komprehensif yaitu dari perspektif pengguna layanan publik terhadap 
kebijakan layanan publik dan sumber daya pelayanan publik pada BPMPP Kabupaten Banyumas.

\section{B. METODE PENELITIAN}

Metode yang digunakan dalam penelitian ini adalah mixed methods. Jenis penelitian ini merupakan penggabungan dua bentuk penelitian yang telah ada sebelumnya yaitu penelitian kualitatif dan penelitian kuantitaif. Menurut Creswell (2009) penelitian campuran merupakan pendekatan penelitian yang mengkombinasikan antara penelitian kualitatif dan kuantitaif. Menurut Sugiyono (2012) menyatakan bahwa metode penelitian kombinasi (mixed methods) adalah suatu metode penelitian yang mengkombinasikan atau menggabungkan antara metode kuantitatif dengan metode kualitatif untuk digunakan secara bersama-sama dalam suatu kegiatan penelitian, sehingga diperoleh data yang lebih komprehensif, valid, reliable, dan obyektif. Pengumpulan data dilakukan melalui kuesioner. Populasi dalam penelitian ini adalah seluruh masyarakat yang pernah mengurus IMB di BPMPP Kabupaten Banyumas pada tahun 2015. Sampel yang diambil sebanyak 40\% dari jumlah populasi, dengan perhitungan 40\% x 256 = 102 sampel.

Dalam penelitian ini menggunakan perspektif pengguna layanan terhadap kinerja layanan Izin Mendirikan Bangunan. Adapun konsep kinerja yang digunakan adalah dengan menggunakan konsep yang dimunculkan oleh Dwiyanto (2008) dengan perincian seperti tabel berikut.

Tabel. Matriks Definisi Operasional

\begin{tabular}{|c|c|c|}
\hline Variabel & Dimensi & Indikator \\
\hline \multirow{9}{*}{$\begin{array}{c}\text { Kinerja } \\
\text { Badan } \\
\text { Penanaman } \\
\text { Modal dan } \\
\text { Pelayanan } \\
\text { Perizinan } \\
\text { (BPMPP) } \\
\text { Kabupaten } \\
\text { Banyumas }\end{array}$} & \multirow{4}{*}{ Produktivitas } & 1. Kejelasan prosedur dan syarat layanan \\
\hline & & $\begin{array}{l}\text { 2. Pelayanan yang mudah dan tidak } \\
\text { berbelit-belit }\end{array}$ \\
\hline & & $\begin{array}{l}\text { 3. Ketepatan waktu dalam memberikan } \\
\text { pelayanan }\end{array}$ \\
\hline & & 4. Sarana pelayanan yang memadai \\
\hline & \multirow{3}{*}{$\begin{array}{l}\text { Kualitas } \\
\text { Pelayanan }\end{array}$} & 5. Kecepatan pelayanan \\
\hline & & 6. Akurasi pelayanan \\
\hline & & 7. Keamanan pelayanan \\
\hline & \multirow{2}{*}{$\begin{array}{l}\text { Responsivitas } \\
\text { Pelayanan }\end{array}$} & 8. Daya tanggap secara umum \\
\hline & & $\begin{array}{l}\text { 9. Kepekaan terhadap keluhan } \\
\text { masyarakat dalam pelayanan Izin }\end{array}$ \\
\hline
\end{tabular}




\begin{tabular}{|c|c|}
\hline & Mendirikan Bangunan \\
\hline & $\begin{array}{l}\text { 10. Tingkat kejelasan informasi tentang } \\
\text { pelayanan yang diberikan }\end{array}$ \\
\hline \multirow{3}{*}{$\begin{array}{c}\text { Responsibilitas } \\
\text { Pelayanan }\end{array}$} & $\begin{array}{l}\text { 11. Kesesuaian pelayanan dengan } \\
\text { prinsisp-prinsip pelayanan }\end{array}$ \\
\hline & $\begin{array}{l}\text { 12. Kesesuaian pelayanan dengan harapan } \\
\text { pengguna layanan }\end{array}$ \\
\hline & $\begin{array}{l}\text { 13. Kesesuaian pelayanan dengan tugas } \\
\text { pokok dan fungsi }\end{array}$ \\
\hline \multirow{2}{*}{$\begin{array}{l}\text { Akuntabilitas } \\
\text { Pelayanan }\end{array}$} & $\begin{array}{l}\text { 14. Konsistensi antara kebijakan layanan } \\
\text { Badan Penanaman Modal dan } \\
\text { Pelayanan Perizinan } \\
\text { dengan aspirasi masyarakat }\end{array}$ \\
\hline & $\begin{array}{l}\text { 15. Kemampuan meningkatkan } \\
\text { kepeduliaan terhadap masyarakat } \\
\text { pengguna layanan }\end{array}$ \\
\hline
\end{tabular}

\section{HASIL PENELITIAN DAN PEMBAHASAN}

\section{Hasil Penelitian}

Tabel Kategori Tingkat Kinerja BPMPP Kabupaten Banyumas

\begin{tabular}{|cccc|}
\hline Skor & Kategori & Frekuensi & Persentase (\%) \\
\hline $30-69$ & Rendah & 86 & 84,3 \\
$70-109$ & Sedang & 13 & 12,7 \\
$110-150$ & Tinggi & 3 & 2,9 \\
\hline Total & & 102 & 100,0 \\
\hline
\end{tabular}

Sumber : data primer diolah, 2015

Tabel di atas menunjukkan bahwa kinerja BPMPP Kabupaten

Banyumas dalam pelayanan IMB masuk pada kategori rendah. Hasil penelitian pada tabel di atas mendukung apa yang telah diungkapkan dalam latar belakang masalah mengenai kinerja pelayanan IMB apabila dilihat dari sisi waktu pelayanan seperti yang terlihat pada tabel di bawah ini.

Tabel. Rekapitulasi Pelayanan IMB 2015

\begin{tabular}{|l|l|l|l|l|l|}
\hline \multirow{2}{*}{ No } & Jenis Layanan & \multicolumn{3}{|c|}{ Jangka Waktu layanan } & \multicolumn{2}{c|}{ Persentase } \\
\cline { 3 - 7 } & $\begin{array}{l}\text { Sesuai } \\
\text { SOP (14 } \\
\text { hari) }\end{array}$ & $\begin{array}{l}\text { Belum Sesuai } \\
\text { SOP } \\
\text { (lebih dari 14 } \\
\text { hari) }\end{array}$ & & \\
\hline 1 & $\begin{array}{l}\text { Izin Mendirikan } \\
\text { Bangunan }\end{array}$ & 20 & 236 & $7,8 \%$ & $92,2 \%$ \\
\hline
\end{tabular}

Sumber: BPMPP, 2015 
Kedua tabel di atas menunjukkan bahwa kinerja pelayanan IMB di BPMPP Kabupaten Banyumas belum memenuhi harapan dari masyarakat pengguna, kinerja pelayanan IMB menunjukkan taraf yang rendah. Rendahnya kinerja BPMPP Kabupaten Banyumas dalam pelayanan IMB terlihat dari beberapa dimensi, antara lain : (1) Produktivitas (2) Kualitas layanan, (3) Responsivitas layanan, (4) Responsibilitas layanan dan (5) Akuntabilitas layanan. Berikut disajikan data hasil sensus yang dihimpun melalui instrumen penelitian dari tiap dimensi dalam variabel kinerja BPMPP Kabupaten Banyumas.

Tabel. Kategori Produktivitas Layanan

\begin{tabular}{lrr}
\hline Kategori & Jumlah & Persentase (\%) \\
\hline Rendah & 99 & 97,1 \\
Sedang & 0 & 0 \\
Tinggi & 3 & 2,9 \\
\hline Jumlah & 102 & 100 \\
\hline
\end{tabular}

Sumber: data primer diolah, 2015

Tabel di atas menunjukkan bahwa kategorisasi kinerja BPMPP Kabupaten Banyumas dilihat dari dimensi produktivitas layanan secara mayoritas berada dalam kategori rendah. Fakta ini didukung pula dengan hasil wawancara dengan salah satu pegawai yang mengatakan bahwa:

"Dalam memberikan pelayanan kepada masyarakat kami selalu berupaya memberikan pelayanan yang terbaik yakni salah satunya dengan memberikan penjelasan mengenai prosedur dan syarat dalam mengurus dokumen. Akan tetapi, kami juga menyadari bahwa dalam hal waktu pelayanan kami masih belum mampu memenuhi harapan masyarakat. Sarana yang kami miliki juga masih kurang memadai."

Tabel. Kategori Kualitas Layanan

\begin{tabular}{lrr}
\hline Kategori & Jumlah & Persentase (\%) \\
\hline Rendah & 57 & 55,9 \\
Sedang & 42 & 41,2 \\
Tinggi & 3 & 2,9 \\
\hline Jumlah & 102 & 100 \\
\hline
\end{tabular}

Sumber: data primer diolah, 2015

Tabel di atas menunjukkan bahwa kategorisasi kinerja BPMPP Kabupaten Banyumas dilihat dari dimensi kualitas layanan secara 
mayoritas berada dalam kategori rendah. Fakta ini didukung pula dengan hasil wawancara dengan salah satu informan yang mengatakan bahwa:

"Saya sudah beberapa kali mengurus IMB di BPMPP, tapi saya merasa belum pernah dilayani dengan cepat, padahal semua persyaratan yang diperlukan sudah saya cukupi. Oh ya saya pernah juga pada saat mengurus IMB dulu SK IMBnya ada kesalahan pengetikan, waktu itu saya langsung complain ke pegawai, tapi responnya lambat. Selain itu sering juga ketika saya sudah membayar biaya pembuatan saya tidak langsung menerima kuitansi pembayaran dan saya harus sering mengingatkan dan meminta kuitansi kuitansi ke petugas".

Tabel. Kategori Responivitas Layanan

\begin{tabular}{lrr}
\hline Kategori & Jumlah & Persentase (\%) \\
\hline Rendah & 69 & 67,6 \\
Sedang & 30 & 29,4 \\
Tinggi & 3 & 2,9 \\
\hline Jumlah & 102 & 100 \\
\hline
\end{tabular}

Sumber: data primer diolah, 2015

Tabel di atas menunjukkan bahwa kategorisasi kinerja BPMPP Kabupaten Banyumas dilihat dari dimensi responsivitas layanan secara mayoritas berada dalam kategori rendah. Fakta ini didukung pula dengan hasil wawancara dengan salah satu informan yang mengatakan bahwa:

"Pernah saya mengurus Izin Mendirikan Bangunan (IMB) di Badan Penanaman Modal dan Pelayanan Perizinan (BPMPP) dan sudah lama sekali baru jadi, saya tidak pernah diberikan informasi oleh patugas mengenai berkas yang saya ajukan. Waktu itu saya sudah melakukan protes ke petugas, tapi mereka tidak segera menanggapi protes saya. Saya melihat bahwa petugasnya tidak ramah dalam melayani saya, saya sering merasa tidak diperhatikan".

Tabel. Kategori Responsibilitas Layanan

\begin{tabular}{lrr}
\hline Kategori & Jumlah & Persentase (\%) \\
\hline Rendah & 61 & 59,8 \\
Sedang & 38 & 37,3 \\
Tinggi & 3 & 2,9 \\
\hline Jumlah & 102 & 100 \\
\hline
\end{tabular}

Sumber: data primer diolah, 2015 
Tabel di atas menunjukkan bahwa kategorisasi kinerja BPMPP Kabupaten Banyumas dilihat dari dimensi responsibilitas layanan secara mayoritas berada dalam kategori rendah. Fakta ini didukung pula dengan hasil wawancara dengan salah satu pegawai yang mengatakan bahwa:

"Jumlah pegawai yang ada di kantor kami memang masih belum cukup, sehingga terkadang kami harus melakukan pekerjaan di luar tugas pokok kami. Keterbatasan ini juga menjadikan kendala bagi kami untuk memberikan pelayanan yang baik kepada masyarakat. Selain itu berbagai aturan yang ada di kantor kami mulai dari peraturan yang dikeluarkan oleh pemerintah pusat maupun daerah sangat banyak dan membingungkan."

Tabel 1. Kategori Akuntabilitas Layanan

\begin{tabular}{lrr}
\hline Kategori & Jumlah & Persentase $(\%)$ \\
\hline Rendah & 96 & 94,1 \\
Sedang & 3 & 2,9 \\
Tinggi & 3 & 2,9 \\
\hline Jumlah & 102 & 100 \\
\hline
\end{tabular}

Sumber: data primer diolah, 2015

Tabel di atas menunjukkan bahwa kategorisasi kinerja BPMPP Kabupaten Banyumas dilihat dari dimensi akuntabilitas layanan secara mayoritas berada dalam kategori rendah. Fakta ini didukung pula dengan hasil wawancara dengan salah satu pegawai yang mengatakan bahwa:

"Waktu saya mengurus IMB dulu pernah saya melihat ada orang lain yang juga mengurus IMB dia tidak ikut mengantri, tapi langsung di layani oleh petugas. Saya sebetulnya merasa tidak terima, karena saya sudah mengantri kok tidak langsung dilayani oleh petugas."

\section{Pembahasan}

Kinerja merupakan salah satu bagian penting dalam organisasi publik guna mengukur keberhasilan suatu organisasi publik dalam mencapai tujuannya. Hal ini sesuai dengan apa yang diungkapkan oleh Keban (2008) mengenai kinerja yakni semakin tinggi kinerja organisasi, semakin tinggi pula tingkat pencapaian organisasi. Sebaliknya, rendahnya kinerja suatu organisasi menunjukkan pula rendahnya pencapaian organisasi tersebut. Dikemukakan pula oleh Julnes (2008: 1450) bahwa 
kinerja harus dibentuk dan bersesuaian dengan misi dan tujuan organisasi. Kinerja meliputi kinerja organisasi, kinerja proses, dan kinerja pegawai. Ketiganya harus berjalan seiring dan sejalan agar organisasi maju dan berkembang. Kinerja dalam suatu organisasi publik penting untuk selalu dilakukan penilaian. Karena kinerja suatu organisasi adalah tingkat kemampuan suatu organisasi dalam memenuhi fungsi serta aturan yang ditetapkan bagi pencapaian tujuan. Apabila sebuah organisasi publik memiliki kinerja rendah, maka akan terjadi ketidakpuasan masyarakat dan menurunnya kepercayaan masyarakat terhadap organisasi publik, serta terhambatnya penyelenggaraan pemerintahan.

Aspek-aspek pengukuran kinerja pelayanan IMB Badan Penanaman Modal dan Pelayanan Perizinan (BPMPP) Kabupaten Banyumas yang dapat dijadikan sebagai tolok ukur dalam menilai kinerjanya yaitu, 1. Produktivitas meliputi kejelasan prosedur dan syarat pelayanan, pelayanan yang mudah dan tidak berbelit-belit, ketepatan waktu dalam memberikan pelayanan, serta sarana pelayanan yang memadai; 2. Kualitas layanan meliputi kecepatan pelayanan, akurasi pelayanan, dan keamanan pelayanan; 3. Responsivitas meliputi daya tanggap secara umum, kepekaan terhadap keluhan masyarakat dalam pelayanan Izin Mendirikan Bangunan, dan tingkat kejelasan informasi tentang pelayanan yang diberikan; 4. Responsibilitas meliputi kesesuaian pelayanan dengan prinsip-prinsip pelayanan, kesesuaian pelayanan dengan harapan pengguna layanan, serta kesesuaian pelayananan dengan tugas pokok dan fungsi; 5. Akuntabilitas meliputi konsistensi antara kebijakan layanan Badan Penanaman Modal dan Pelayanan Perizinan (BPMPP) dengan aspirasi masyarakat dan kemampuan meningkatkan kepeduliaan terhadap masyarakat pengguna layanan (Dwiyanto, 2006)

Rumusan masalah dalam penelitian ini adalah seberapa besar tingkat kinerja pelayanan Izin Mendirikan Bangunan (IMB) Badan Penanaman Modal dan Pelayanan Perizinan Kabupaten Banyumas. Penelitian ini memiliki tujuan untuk mengukur besarnya tingkat kinerja 
pelayanan Izin Mendirikan Bangunan (IMB) Badan Penanaman Modal dan Pelayanan Perizinan Kabupaten Banyumas. Hasil distribusi frekuensi variabel kinerja menunjukkan bahwa kinerja pelayanan Izin Mendirikan Bangunan Badan Penanaman Modal dan Pelayanan Perizinan (BPMPP) Kabupaten Banyumas secara umum menunjukkan masih rendah.

Tabel. Kategori Tingkat Kinerja BPMPP Kabupaten Banyumas Berdasarkan Dimensi

\begin{tabular}{l|c|r|c|}
\hline \multirow{2}{*}{$\begin{array}{c}\text { Dimensi } \\
\text { Kinerja BPMPP }\end{array}$} & \multicolumn{3}{|c|}{ Kategori } \\
\cline { 2 - 4 } Produktivitas & $99(97,1 \%)$ & \multicolumn{1}{c|}{ Sedang } & Tinggi \\
Kualitas Layanan & $57(55,9 \%)$ & $42(41,2 \%)$ & $3(2,9 \%)$ \\
Responsivitas & $69(67,6 \%)$ & $30(29,4 \%)$ & $3(2,9 \%)$ \\
Responsibilitas & $61(59,8 \%)$ & $38(37,3 \%)$ & $3(2,9 \%)$ \\
Akuntabilitas & $96(94,1 \%)$ & $3(2,9 \%)$ & $3(2,9 \%)$ \\
\hline Sumber: data primer diolah, 2015 &
\end{tabular}

Tabel di atas menunjukkan bahwa kategorisasi kinerja BPMPP Kabupaten Banyumas dilihat dari dimensinya secara mayoritas berada dalam kategori rendah. Fakta ini memberikan gambaran bahwa kinerja yang rendah dari BPMPP Kabupaten Banyumas mendapatkan kontribusi secara berurutan dari rendahnya produktivitas layanan, akuntabilitas layanan, responsivitas layanan, responsibilitas layanan, dan kualitas layanan. Sehingga dapat ditarik kesimpulan bahwa kinerja pelayanan IMB BPMPP Kabupaten Banyumas buruk. Uji distribusi Frekuensi terhadap variabel kinerja pelayanan IMB BPMPP Kabupaten Banyumas telah menunjukkan bahwa kinerjanya masih rendah/buruk.

\section{KESIMPULAN DAN SARAN}

\section{Kesimpulan}

Berdasarkan hasil analisis distribusi frekuensi terhadap Kinerja pelayanan Izin Mendirikan Bangunan (IMB) Badan Penanaman Modal dan Pelayanan Perizinan (BPMPP) Kabupaten Banyumas serta hasil 
wawancara dapat diambil suatu kesimpulan bahwa kinerja pelayanan IMB BPMPP Kabupaten Banyumas masih masuk kategori rendah. Demikian pula setelah dikontrol dengan variabel jenis kelamin, usia, tingkat pendidikan dan jenis pekerjaan kinerja pelayanan IMB BPMPP Kabupaten Banyumas masih masuk kategori rendah. Kinerja pelayanan IMB BPMPP yang rendah mendapatkan kontribusi dari dimensi-dimensi kinerjanya, secara berurutan kontribusi tersebut didominasi dimensi produktivitas layanan dan akuntabilitas layanan, kemudian responsivitas, responsibilitas dan kualitas layanan.

\section{Saran}

Berdasarkan kesimpulan di atas, maka untuk meningkatkan kinerja lembaga pelayanan perizinan perlu dilakukan berbagai upaya peningkatan utamanya adalah peningkatan produktivitas dan akuntabilitas layanan. Upaya peningkatan kinerja lembaga pelayanan perizinan dilakukan dengan:

a. Meningkatkan produktivitas dengan cara meningkatkan kedisiplinan kerja para pegawai baik disiplin waktu maupun disiplin dalam menyelesaikan tugas dan tanggungjawabnya, mengadakan sarana dan prasarana layanan yang lebih baik lagi, melakukan upaya pembinaan dan pemahaman terhadap pegawai bahwa masyarakat perlu dilayani dengan baik, serta memperbanyak jumlah papan informasi mengenai alur dan prosedur pengurusan perizinan dan prosedur.

b. Meningkatkan Akuntabilitas dengan memberikan pelayanan yang lebih transparan dalam berbagai pelayanan yang diberikan kepada masyarakat utamanya dalam hal biaya yang harus dikeluarkan oleh masyarakat pengguna layanan.

c. Meningkatkan Responsivitas dengan memberikan pendidikan dan pelatihan secara berkala, agar pegawai terbangun kepekaannya.

d. Meningkatkan Responsibilitas dengan menerapkan pembagian tugas pokok dan fungsi yang lebih jelas kepada masing-masing pegawai, 
agar pegawai lebih fokus dan terarah, serta mampu memenuhi harapan masyarakat pengguna layanan

e. Meningkatkan kualitas layanan dengan cara memperbaiki sistem pelayanan agar masyarakat dapat dilayani dengan cepat, akurat, dan aman

\section{E. DAFTAR PUSTAKA}

\section{Buku :}

Creswell, John W. 2009. Research Design Pendekatan Penelitian Kualitatif, Kuantitatif, dan Mixed. Yogyakarta: Pustaka Pelajar. Penterjemah Achmad Fawaid.

Creswell, John W. 2009. RESEARCH DESIGN (Qualitative, Quantitative, and Mixed Methods Approaches. USA: SAGE Publications, Inc.

Dwiyanto, Agus. 2008. Reformasi Birokrasi Publik di Indonesia. Yogyakarta: Gadjah Mada University Press.

-----------------, 2006. Mengembalikan Kepercayaan Publik Melalui Reformasi Birokrasi. Jakarta: Gramedia Pustaka Utama.

Julnes, P. D. 2008. "Performance Measurement". In E. M. Berman, \& J. Rabin, Encyclopedia of Public Administration and Public Policy (pp. 1450-1454). USA: Taylor \& Francis Group, LLC.

Keban, Y.T. 2008. Enam Dimensi Strategis Administrasi Publik. Yogyakarta: Gama Media.

Sugiyono. 2007. Metode Penelitian Administrasi dilengkapi dengan metode $R \& D$. Bandung: Alfabeta.

. 2012. Metode Penelitian Administrasi dilengkapi dengan metode $R \& D$. Bandung: Alfabeta

\section{Jurnal :}

Pane, N.M. dan Febri Yuliani. 2012. Kualitas Pelayanan Publik dalam Pengurusan IMB. Jurnal Kebijakan Publik FISIP Universitas Riau Vol 3 No 1 Hal: 51-57. 
Rahmawati, P, 2012. Analisis Kinerja Pegawai Kantor Dinas Kesehatan Kabupaten Bintan Kepulauan Riau. Tesis Universitas Indonesia Depok (dipublikasikan).

Ritz, Adrian. 2009. Public service motivation and organizational performance in Swiss federal government. International Review of Administrative Sciences: SAGE. Hal 53-78.

Saniadi, Kurnia. 2008. Analisis Kinerja Kantor Pelayanan Terpadu Dan Perijinan Kabupaten Grobogan. Tesis Universitas Diponegoro Semarang (dipublikasikan).

Yonanda, I., Mochamad Makmur dan Ramulo Adiono. 2015. Efektivitas Pelayanan Izin Mendirikan Bangunan (IMB) dalam Sektor Indutrsi Pariwisata di Kota Batu. Jurnal Administrasi Publik Universitas Brawijaya Vol 1. No.1. Hal: 70-78.

\section{Sumber Lain :}

Peraturan Daerah Kab. Banyumas Nomor 17 tahun 2011 tentang Organisasi dan Tata Kerja Lembaga Teknis Daerah Kabupaten Banyumas

Perda Nomor 7 tahun 2011 tentang Izin Mendirikan Bangunan

Peraturan Bupati Banyumas Nomor 50 tahun 2014 tentang pendelegasian wewenang perizinan kepada kepala badan penanaman modal dan pelayanan perizinan Kabupaten Banyumas

Detikcom, Tanggal 31 Agustus 2015: "Rizal Ramli : 124 perizinan di 20 kementerian dan lembaga tidak masuk akal". http://news.detik.com/berita/3006222/rizal-ramli-124-perizinan-di-20kementerian-dan-lembaga-tidak-masuk-akal 